\title{
O DIVINO EM UM TERRITÓRIO QUILOMBOLA NO MARANHÃO
}

THE FEAST OF THE HOLY SPIRIT IN A "QUILOMBOLA" TERRITORY IN MARANHÃO

\section{Maria da Consolação Lucinda}

Pesquisadora associada na Universidade Estadual do Maranhão (UEMA). Pós-doutorado pelo Programa de Pós-graduação em Cartografia Social e Política da Amazônia da Universidade Estadual do Maranhão (PPGCSPA/UEMA). Integra o Programa Direitos Humanos, Educação e Cidadania (Novamerica). 


\section{RESUMO}

Este artigo apresenta uma breve análise dos aspectos relativos à devoção ao Divino Espírito Santo em um território quilombola localizado no município de Itapecuru Mirim, no estado do Maranhão. A análise é empreendida por meio das noções de "dádiva" e "prece", consoante a reflexão de Marcel Mauss (2003, 2009) sobre esses conceitos e os fenômenos a eles referidos, sugerindo uma relação entre a devoção ao Divino e as estratégias acionadas pelos quilombolas na afirmação ao direito territorial.

Palavras-chave: Festa do Divino Espírito Santo; pagamento de promessa; território; dádiva; prece.

\section{ABSTRACT}

This article presents a brief analysis by means of some aspects related to the devotion of the Divine Holy Spirit in a quilombola territory located in the municipality of Itapecuru Mirim, Maranhão. The analysis is undertaken through the notions of "gift" and "prayer", according to Marcel Mauss's reflection on these concepts and the phenomena constituted by them, suggesting a relationship between devotion to the Divine Holly Spirit and the strategies triggered by quilombolas in the affirmation of the right to territory.

Keywords: feast of the divine holy spirit; promise payment; territory; gift, prayer. 


\section{Introdução}

Ao descrever as condições que deram origem ao território quilombola de Santa Rosa dos Pretos, no Maranhão, os líderes locais relatam que as terras foram doadas a um grupo formado por sete famílias que realizavam trabalho escravo na lavoura de uma fazenda pertencente à família do barão de Santa Rosa, no século XIX. Nos relatos consta ainda que tal fazenda era um local conhecido pelos castigos físicos infringidos aos trabalhadores escravizados e abrigava uma espécie de "centro de punição" na região.

Na interpretação de Anacleta Pires da Silva, moradora do território Santa Rosa dos Pretos, nessas terras de doação e liderança local, essa referência à titularidade não expressa um ato de bondade, mas revela uma tentativa de apagamento da memória do terror que imperou ali, através da escravização e dos modos como operava o sistema que estruturava as relações sociais naquele tempo. Para ela, a doação deve ser considerada uma reparação às maldades perpetradas naquelas terras durante o regime escravocrata e atualizadas através de violações e desrespeitos aos direitos dos quilombolas.

As situações de conflitos decorrentes de desrespeitos e violações sistemáticas de direitos dos quilombolas pautam agendas políticas desse movimento e, em especial, das lutas por regularização fundiária. A atual geração dos moradores desse território faz memória das lutas, das formas de organização e, sobretudo, dos enfrentamentos que têm sido feitos desde os anos de 1950 em Itapecuru Mirim.

Uma das lutas protagonizadas pelos quilombolas de Santa Rosa dos Pretos é contra a duplicação da BR I35, rodovia que liga o Maranhão ao Piauí. O impacto dessa duplicação sobre o ambiente e os modos de viver dos moradores foi assunto da primeira conversa com Anacleta, em junho de 20I5. São vários os problemas e os riscos que a duplicação representa para os moradores daquele território, começando pela ameaça à integridade de edificações, como a capela centenária, localizada às margens dessa rodovia. É nessa capela que a Festa do Divino é realizada. Também estão sob risco um terreiro de mina, bem como residências de líderes, como as casas da própria Anacleta, de Elias Pires Belfort e muitas outras localizadas ao longo do percurso que sofre os impactos da construção da BR I35 desde que a estrada dividiu o território ao meio.

Ao se reportarem aos enfrentamentos, os moradores mencionaram um protesto realizado em 20I4, que culminou com o bloqueio da Estrada de Ferro Carajás (EFC), operada pela mineradora multinacional Vale S.A. Participaram desse bloqueio à EFC mais de quinhentos quilombolas de Itapecuru Mirim, em uma manifestação que visava chamar atenção da mineradora e do poder público para a importância de se consultar a população sobre a duplicação 
da ferrovia, que estava em curso desde 2013. O direito à consulta prévia, livre e informada dos povos afetados por projetos públicos e privados é garantido pela Convenção I69 da Organização Internacional do Trabalho (OIT), da qual o Brasil é signatário. O protesto visava também cobrar do Governo Federal o cumprimento de demandas relativas à demarcação das terras remanescentes de quilombos.

Decididos a conseguir um espaço de negociação, os quilombolas acamparam sobre os trilhos da ferrovia, tendo uma base de apoio para preparar refeições, usar banheiros etc., no clube comunitário localizado entre a EFC e a BR I35, no povoado Santa Rosa. Para manter o ânimo dos manifestantes, diariamente eram realizadas atividades culturais envolvendo canto, dança com Tambor de Crioula etc., dando compasso ao enfrentamento.

Nesse momento, assim como em vários outros conflitos que enfrentaram, a assimetria de poder levou, em alguma medida, a que a balança pendesse para o lado da companhia mineradora. Em outros casos foram empresários e/ou fazendeiros que, ao desobedecer aos mandados judiciais, ganham vantagem em relação aos quilombolas. Além da organização para o cuidado e a atenção às dimensões ordinárias da vida cotidiana, como a realização de atividades relativas à reprodução dos meios de existência, as ações de resistências e os enfrentamentos demandam esforços contínuos da comunidade.

Um dos desdobramentos desse evento em 2014 foi o processo movido pela Vale S.A., com base em um boletim de ocorrência, contra alguns líderes quilombolas, ainda naquele ano em que a EFC foi bloqueada. Nessa ordem social, o poder da palavra e o poder da lei não são garantias de direitos. Apelar para o Divino, para o Sagrado, desde os tempos imemoriais tem sido um dos caminhos em busca de respostas às demandas e questões tanto no âmbito pessoal quanto no coletivo.

Conheci o território de Santa Rosa dos Pretos poucas semanas depois do primeiro encontro que tive com Elias e Anacleta na sede do Instituto Nacional de Colonização e Reforma Agrária (Incra), em São Luís (MA), em 2015. Minha aproximação com os quilombolas de Santa Rosa dos Pretos se deu por ocasião da atualização de informações contidas no laudo antropológico do território. Esse documento foi tomado como referência para a elaboração de uma narrativa a respeito do local, que integra a Coleção Terras de Quilombo. ${ }^{1}$ A partir dessa que foi a primeira de várias visitas que favoreceram meu diálogo com algumas famílias, pude participar de celebrações e eventos ordinários e extraordinários, como um protesto em abril de 20I6. Foi um

\footnotetext{
${ }^{1}$ Coleção elaborada no âmbito do Projeto Linguagem Pública, coordenada por uma equipe de pesquisadores da Universidade Federal de Minas Gerais (UFMG).
} 
ato contra a votação pelo impeachment da então presidenta Dilma Rousseff, com o bloqueio da BR I35. Aconteceu nas proximidades da capela centenária em que se celebra a Festa do Divino de Santa Rosa, na mesma altura em que foi feito o bloqueio da Estrada de Ferro Carajás, em setembro de 2014 .

As relações e interações entre diferentes comunidades ou povoados, territórios quilombolas, bairros e cidades desenham e redesenham redes sociais que são tecidas a partir da religiosidade, conectando parentesco, fazendo articulações com a política a partir de contornos e condições próprias de cada território, atualizando elementos da tradição e do pertencimento cultural. Essas redes conectam humanos, não humanos, artefatos, territórios, animais, alimentos etc.

Anacleta fala de inspiração com base em valores de matriz africana, reportando-se a alguns ofícios exercidos em Santa Rosa dos Pretos. Através dos saberes das "mães de terreiros" e de seus filhos, e das trocas solidárias entre os quilombolas, esse patrimônio vai sendo mantido pela comunidade. Artefatos como tambores e cabaças, e a composição de cantigas, pontos, enfim, de músicas são percebidos por ela como uma recorrência da utilidade e da centralidade que ocupam no Tambor de Mina, no Tambor de Crioula, na Festa do Divino Espírito Santo etc.

[...] nós tocamos as caixas, fazemos as roupas do império, os bordados. Tudo é feito na comunidade, então não é um recurso tão valioso diante do capitalismo que está aí, que põe milhões e milhões para uma pequena coisa, mas é rico para nós. No nosso entendimento, o capital está pequeno diante do preço dessas coisas que a gente confecciona. É o valor que nós temos. Esse patrimônio que é fazer caixa, que é o fazer dessas roupas, que é o bordado dessa roupa. Então nós vivemos dessas inspirações e desses trabalhos feitos por nós. (informação verbal). ${ }^{2}$

A devoção ao Divino no território de Santa Rosa dos Pretos tem sido passada da geração mais antiga para a mais recente, que procura manter os ensinamentos, aprendendo e ensinando, vendo e sentindo o mundo através do som do tambor que louva os santos, os encantados e os voduns, no toque das caixas e nas canções entoadas pelas caixeiras Missionárias do Divino pela Fé e Devoção. ${ }^{3}$

\footnotetext{
${ }^{2}$ Anacleta Pires da Silva, moradora do território quilombola Santa Rosa dos Pretos. Conversa gravada em junho de 2015.

${ }^{3}$ As manifestações religiosas propriamente ditas têm como referências os terreiros de Tambor de Mina e as capelas católicas. As festividades em louvor aos santos são realizadas em capelas como as de Nossa Senhora da Conceição e Sant'Ana, celebrando Santo Antônio, Sant'Ana, Nossa Senhora da Conceição e São Sebastião.
} 
Este artigo está dividido em quatro tópicos. No primeiro, situo o território quilombola de Santa Rosa dos Pretos a partir de marcos referidos a mobilizações políticas pela terra no Maranhão; assinalo a relação entre o papel desempenhado pela Igreja Católica no contexto da luta pela terra, através de instâncias institucionais que seguem acompanhando essa luta no país nos dias de hoje. No segundo tópico, ressalto o papel do festeiro e seu desempenho durante a realização do evento a partir da interpretação do pagamento da promessa ao Divino no sentido da dádiva, e faço uma breve descrição do desenrolar dos momentos ritualizados da Festa do Divino do povoado Barreira Funda, tomando a apresentação das caixeiras como ângulo para estruturar a descrição. No terceiro tópico, procuro estabelecer uma relação entre as noções de "dádiva" e "prece" como fenômenos sociais consoante a abordagem de Marcel Mauss e o sentido do pagamento da promessa na Festa do Divino em questão.

\section{Mobilizações da Igreja, regularização da terra e reivindicação do território}

A participação e o protagonismo na luta pelo direito a terra são questões centrais na experiência de vida de moradores do território de Santa Rosa dos Pretos, como "Seu" Libânio Pires da Silva e "Seu" Benedito Pires Belfort. A partir da década de I950, ainda muito jovens e acompanhando os pais, eles se envolveram nas mobilizações políticas por autonomia, atuando em prol da regularização fundiária. Naquele contexto, "[por] toda a extensão do Vale do Itapecuru, sucediam-se disputas pela posse da terra e pela livre comercialização do arroz e do coco babaçu" (ALMEIDA, 20I5, p. 30).

Desde a efervescência das mobilizações que perduram até os dias de hoje, a participação na organização sindical tem um componente identitário importante e que circunscreve diferentes dimensões do território e do âmbito coletivo da vida cotidiana. Almeida (2015, p. 69), ao destacar as estratégias acionadas pela Igreja Católica diante dos "conflitos que separavam 'lavradores e trabalhadores agrícolas' dos grandes proprietários e pecuaristas", registra "formas de mobilização" promovidas e organizadas por esta instituição. Menciona as Semanas Ruralistas celebradas com essa finalidade e que consistiam em "grandes festejos da municipalidade, valorizando a cultura e a produção local”. Em Itapecuru Mirim foi realizada VI Semana Ruralista, em I957. O autor lembra ainda que "as cerimônias rituais reforçavam a coesão social e buscavam a 'harmonia' pelo esforço da identidade conferida pelo regionalismo" (p. 69).

As lutas pela regularização agrária e pela afirmação de direitos formam um dos capítulos mais importantes das mobilizações políticas por autonomia em nosso país. "O movimento sindical dos trabalhadores rurais no Estado do Maranhão se desenvolveu fundamentalmente a 
partir das resoluções aprovadas na II Conferência Nacional de Trabalhadores Agrícolas [...] realizada em 1954" (ALMEIDA, 2015, p. 2I). As formas organizativas autônomas e abrangentes experimentadas pelos coletivos que se autodesignam como quilombolas guardam relação de continuidade com essas pautas e bandeiras.

Essas lutas ganharam impulso e se adensaram com o apoio da Igreja Católica progressista naquele contexto, em especial a partir dos anos 1970, através das Comunidades Eclesiais de Base (CEBs) e de organismos institucionais, como a Comissão Pastoral da Terra (CPT) e o Conselho Indigenista Missionário (Cimi). Os apoios podem ter se diversificado, mas aquele conferido pela Igreja Católica se consolidou e conseguiu se atualizar incorporando a pauta identitária quilombola.

Seu Libânio e Seu Benedito são referências para seus filhos e netos, que também atuam como líderes no movimento quilombola. Ainda hoje, as lutas visam em grande medida à regularização fundiária, embora as questões que abrangem tenham se tornado mais complexas à medida que se obtiveram conquistas legais se diversificaram os atores políticos. A consulta prévia, livre e informada se tornou direito e se inscreve no rol de temas enfrentados em situações de conflito e na pauta de reivindicações dos movimentos quilombolas.

Cabe observar que o uso da categoria quilombola e/ou do conceito de quilombo aqui guarda relação com o debate promovido no âmago dessas lutas. Trata-se de uma referência que se pauta na ressignificação do conceito a partir dos processos de reivindicação e afirmação de direitos e garantias, segundo a definição proposta no artigo 68 dos Atos das Disposições Constitucionais e Transitórias (ADCT), conforme a Constituição Federal.

Santa Rosa dos Pretos é um território quilombola considerado "uma escola que ajuda no aprendizado dos que estão à sua volta", referência quando se trata de participação e cooperação entre lideranças quilombolas. Essa é a opinião de Seu José da Conceição da Silva, morador do território quilombola Monge Belo. Ele lançou mão de uma figura de linguagem para dizer que aquele território é "o coração do corpo formado pelos territórios quilombolas que estão ao seu redor". ${ }^{4}$ O reconhecimento dessa liderança foi manifestado para sustentar a importância do intercâmbio e das redes de apoio e solidariedade que o movimento quilombola representa. A opinião de Seu Zé da Conceição ajuda a ver Santa Rosa dos Pretos para além das fronteiras do

${ }^{4}$ Informação obtida a partir de conversa com os referidos agentes, em junho de 2015, na sede do Incra em São Luís, Maranhão. 
território e a identificar na memória as situações de conflitos enfrentados na região. ${ }^{5}$ As manifestações coletivas que reúnem líderes de vários territórios quilombolas mostram que o "corpo" é insubmisso e resiste, apesar das violências sofridas.

Morador do povoado Barreira Funda, Seu Benedito Pires Belfort relatou que era ainda jovenzinho quando começou a perceber o sentido das mobilizações por autonomia e processos de resistência diante dos conflitos agrários na região do Vale do Itapecuru Mirim. São muitas décadas de protagonismo e participação social.

Os ditos e os não ditos no relato de Seu Benedito ajudam a perceber a relação entre religião, política e sociedade, ao destacar o papel institucional desempenhado pela Igreja Católica na organização dos trabalhadores rurais. As Semanas Ruralistas eram festejos realizados pela Igreja para a valorização da cultura e da produção local, e dão dimensão da influência que teve nas formas organizativas dos territórios quilombolas. Almeida (2015), ao apresentar as "formas de mobilização" dessa instituição, enumera o calendário, indicando as cidades em que os eventos foram realizados. A VI Semana Ruralista foi realizada em Itapecuru Mirim, em 1957.

A preparação da Festa do Divino envolve a elaboração de um calendário e, portanto, de um planejamento antecipado, demandando encontros, reuniões e comunicação interna e externa. A realização do festejo é concebida como um trabalho coletivo, mas sua organização é de responsabilidade, em geral, ou de um casal de festeiros ou de uma família, como acontece no povoado da Barreira Funda, em Santa Rosa dos Pretos; e na comunidade Canelatiua, em Alcântara.

A realização da festividade é feita em etapas que culminam com a instalação simbólica do "Império", ou seja, a celebração da coroação do imperador, que implica o oferecimento de banquete comunitário, festejo com atração musical etc. A constituição da "corte" envolve definições e negociações prévias, como a escolha do imperador, que desempenha o papel de acolher e recepcionar os convidados.

A festa também é concebida como um tempo em que se vive, se vê e se lê na paisagem local, de maneira ritualizada, algumas referências cotidianas de sociabilidade. Essa celebração evoca elementos significativos dos modos de ser quilombola e da conexão entre território, práticas religiosas, organização, parentesco e política. Assume um sentido prático ao envolver modos de viver

\footnotetext{
${ }^{5}$ As solidariedades que as formações quilombolas construíram, os seus esforços de organização política, a comunhão de valores e o intercâmbio cultural que estabeleceram de modo progressivo entre si, opondo-se aos brancos, são fatores importantes na constituição de suas identidades.
} 
que põe em relação seres humanos e a terra, a água, a mata, os animais, a moradia etc. Coloca humanos e não humanos em relação, e dinamiza a inter-relação entre homens e mulheres.

A difusão do culto do Divino remonta às festas realizadas em Portugal a partir do século XIV. É tida como uma das mais antigas e difundidas expressões religiosas no Brasil. As festividades se associam à comemoração do Dia de Pentecostes, que acontece cinquenta dias após a Páscoa, conforme a narrativa bíblica. Nessa referência simbólica à descida do Divino Espírito Santo sobre os apóstolos de Jesus Cristo, sob a forma de línguas de fogo, outra imagem importante é a de uma pomba. É uma celebração da esperança no porvir, uma nova era.

\section{Devoção ao Divino Espírito Santo em um território quilombola}

As mobilizações das comunidades e as festividades religiosas são eventos que envolvem participação de parentes e amigos que vivem ou não no mesmo povoado. Abrangem também parentes estabelecidos em outros territórios, outras cidades e outras regiões do estado. Isso depende da magnitude da festa, podendo representar um momento catalisador e de fortalecimento de laços e vínculos familiares, bem como de trocas e apoios comunitários.

A Festa do Divino celebrada no povoado Santa Rosa tem um caráter comunal mais amplo que aquela da Barreira Funda, com incumbências e responsabilidades que levam a que haja alternância da participação dos encarregados de sua organização. Por ter seu início relacionado com o pagamento de uma promessa, o encarregado da Festa da Barreira Funda foi até 2018 o mesmo festeiro, embora o evento contasse com a participação de outras famílias do povoado. A possibilidade de participação na organização e igualmente na retribuição a uma prece atendida pelo Divino é sempre possível, mesmo em casos como o da Barreira Funda. Ser encarregado ou ser dono(a) de uma festa é um papel que confere prestígio, mas representa, especialmente, uma grande responsabilidade.

A realização de um evento em retribuição ao Sagrado, no caso, ao Divino, tem sua margem de risco, uma vez que a intenção é agradar ao Divino. Para que transcorra dentro dos parâmetros estabelecidos e do ritual que representa, a festa demanda esforço pessoal, recursos e, em certa medida, prestígio.

O papel do(a) encarregado(a) confere distinção quando a festa é bem-sucedida e isso depende da competência demonstrada na organização e na mobilização de participantes que desempenham tarefas fundamentais para esse sucesso. O prestígio e a autoridade dos encarregados são inegáveis por mostrarem a competência de quem organiza um evento pleno de 
simbolismos. Além disso, não se pode perder de vista que a Festa do Divino é uma expressão da relação entre humanos e não humanos, envolvendo forças humanas e também não humanas.

A Festa do Divino se compõe de vários momentos, sendo alguns mais ritualizados e outros que visam apenas à confraternização e ao entretenimento. A celebração que acontece na igreja marca o Dia de Pentecostes e se deve à tradição associada ao catolicismo. A primeira celebração do Pentecostes da qual participei no Maranhão, na Igreja de São Pantaleão, localizada em São Luís, teve a liturgia organizada por representantes da Casa de Nagô. ${ }^{6}$ A relação estreita entre salões e terreiros de Tambor de Mina e a devoção ao Divino Espírito Santo não são uniformes e talvez se possa dizer que derivam da própria introdução dessa devoção no Maranhão.

A missa que marcou a finalização da festa na Barreira Funda foi celebrada em uma sextafeira, dois dias antes da derrubada do mastro, na capela dedicada à Nossa Senhora da Conceição. No interior da capela poderiam ser acomodadas cerca de cinquenta pessoas sentadas, mas a celebração foi assistida também por pessoas que já estavam postadas às janelas que, naquele dia, era de longe um lugar privilegiado para participar do evento, devido ao forte calor. Os insetos voando em torno das lâmpadas não ofuscaram a atuação das caixeiras que, através da marcação percussiva, são fundamentais para o acompanhamento da apresentação do Império. Durante a sessão das caixeiras foi possível observar momentos significativos da festividade: o desenrolar dos momentos ritualizados; a passagem do solene ao irreverente, à brincadeira na comemoração guiada pelas toadas, pelos toques e pelos versos "puxados" nos atos performados.

A exposição dos símbolos rituais da festa na capela parecia mais simples que a observada em altares organizados nos terreiros, como os da Casa de Nagô e da Casa das Minas. Nesses últimos, os altares são adornados com toalhas nas cores que representam o Divino: branca, vermelha, dourada e azul, e são dispostos artefatos simbólicos como a coroa, uma pomba, fitas e velas. À frente foram arrumados genuflexórios ou tapetes para quem desejasse fazer orações, pedidos e promessas ajoelhado diante do altar.

Outro elemento simbólico importante na Festa do Divino é a bandeira que, empunhada pelo "alferes", percorre ruas, caminhos e povoados do território para anunciar que o Sagrado está de visita no local. É momento também de recolher donativos e esmolas para a realização da festa. As cores da bandeira representam a realeza, a monarquia humana e igualmente a Divina; a força e o poder. Simboliza a autoridade, a soberania e o poder constituído, reconhecidos e estabelecidos

\footnotetext{
${ }^{6}$ Ferreti (2001, p. 79) denomina este que vem a ser um dos mais antigos terreiros de São Luís de coirmão da Casa das Minas. A Casa de Nagô, apesar de ter uma identidade marcante e traços bem diferenciados, aproxima-se bastante da Casa das Minas.
} 
pelos humanos em nome do Divino. Decorada com uma pomba do Divino Espírito Santo, seu mastro é adornado com fitas coloridas.

No final da missa, as mães iniciaram a saudação ao Império e aos demais integrantes deste, ali representados de modo coreografado, guiadas pelo toque da caixeira régia e orientadas pela entoação das cantigas. A ritualização de movimentos e expressões corporais, obedecendo às regras de etiqueta, estabeleceu uma ordem de saudações tendo por base o toque das caixeiras. Os devotos se precipitaram na direção do altar para saudarem a "santa croa", a pomba e os demais artefatos simbólicos dos rituais ali dispostos que aludem à presença do Divino Espírito Santo entre os humanos.

Precedidas pelo alferes da bandeira, que abria o caminho em passos cadenciados, as caixeiras lideradas pela caixeira régia finalizaram as saudações saindo em procissão. O cortejo seguiu em direção ao mastro, localizado cerca de dez metros da porta da capela. Ali, a reverência foi feita em movimentos circulares, com o toque da caixa e o canto das caixeiras. No topo do mastro, uma bandeira com dimensões menores que aquela empunhada pelo alferes tremulava e sobrepunha os vários elementos que podiam ser vistos como adornos, mas que estavam se recompondo através da sacralização operada pela repetição do ato encenado cada vez que o cortejo os saudava. ${ }^{7}$

Decorada com ramos de coqueiro, flores e frutas - especialmente bananas - havia no mastro uma garrafa de aguardente. É costume se ofertar cédulas de dinheiro também, mas não observei nesta festa específica se isso tinha sido feito. O levantamento do mastro marca o início do festejo. Só tive a oportunidade de acompanhar o derrubamento do mastro da festa da Barreira Funda, pois ele fora levantado na semana anterior.

Na manhã seguinte, o primeiro ato foi uma visita à casa do mordomo régio. Os representantes do Império saíram de suas respectivas residências para compor o cortejo organizado pelas caixeiras. À porta de suas casas, em companhia de orgulhosas e desveladas mães, estavam o imperador, a imperatriz e os integrantes da corte de 2015 da Festa do Divino. Usavam trajes diferentes um dos outros, sofisticados como os do dia anterior, mas com cores e modelos distintos.

Depois da saudação iniciada na casa do mordomo régio, em cuja sala uma mesa farta de bolos e doces foi fotografada, observada e certamente muito cobiçada, o cortejo seguiu em um espaço aberto que funciona como praça e centro da comunidade. Ali aconteceria o abate de um

\footnotetext{
7 Todos os artefatos são considerados e reverenciados como sagrados e no ritual celebrado anualmente, a sacralização é atualizada. A bandeira também é um artefato sacralizado.
} 
boi, cuja carne é oferecida no almoço daquele dia e também no de domingo, junto com o de um porco, em um ritual sob uma árvore frondosa. A carne de gado e, em menor medida, a suína, tal como os bolos e os doces, são símbolos importantes da abundância que marca essa ocasião especial na vida comunitária.

O percurso foi realizado ao som da caixa, em tom marcial, mas apenas até a chegada. Em seguida, o registro mudou e a cena formada na sequência teve como centro os dois animais - em especial o boi - que seriam abatidos. Na ocasião, o público presente era relativamente maior que aquele formado durante a visita à casa do mordomo régio, mas não era uma aglomeração densa de pessoas. Uma meia lua se formou a partir do lugar em que se encontravam os animais e o torno das árvores onde estavam amarrados.

Enquanto no cenário em que acontecia o ritual do abate os últimos detalhes iam sendo concluídos, a pilhéria e a jocosidade das caixeiras davam o tom do ambiente. Elas provocavam o encarregado do abate, sugerindo que ele não conseguiria realizar a tarefa. $O$ tom de brincadeira permaneceu até que a preparação foi concluída. Foi preciso reforçar o nó da corda que amarrava o boi, amolar a faca e esperar a chegada do encarregado da festa; ninguém parecia ter pressa.

Naquela festa específica, as caixeiras cantavam atentas aos que se juntavam à plateia que assistia ao abate e, de modo furtivo, surpreendiam os recém-chegados atando-lhes uma fita no pulso. Essa era a maneira de alertar para o protocolo daquele momento. Quem recebia esse alerta deveria pagar uma prenda em dinheiro por estar quebrando a etiqueta da festa. Seu Benedito recebeu a fita, pois trajava calças compridas na cor preta. O uso de shorts ou de bermudas - de qualquer cor - infringia essa etiqueta, assim como de qualquer peça de roupa na cor preta. A irreverência e a descontração davam o tom daquele momento, fosse pelo improviso das toadas "puxadas" pelas caixeiras, fosse pelo "repente" que descrevia os movimentos das pessoas ou a cena que transcorria lentamente com a preparação que antecede o abate do boi.

A noção de sacrifício passou a dar o contorno do momento do abate. As brincadeiras das caixeiras cederam lugar a um registro solene, com cânticos mais melódicos e melancólicos, com referências ao sacrifício. Como se estivesse percebendo o que lhe sobreviria, o boi começou a mugir. Era um lamento delirante, uma recusa a se render ao que lhe estava reservado. Aquele final deveria transcorrer sem sobressaltos. Uma atmosfera de encantamento se produzia a partir do toque das caixeiras e do som melodioso de suas vozes.

A observação da cena permitia que se notasse uma influência das cantigas entoadas e a rendição do animal. Sem condições de resistir, ele tombou lenta e compassadamente, vencido sem querer sucumbir. A cena parecia uma evocação à reciprocidade entre humanos e não 
humanos - seres sacralizados. O animal estava em cena como vítima sacrificial. O que se seguiu ao abate, a distribuição da carne aos participantes da festividade, fosse in natura, fosse através do almoço, era ainda a extensão do sacrifício. Esse momento foi um ato em Ação de Graça pelo festeiro, pela resposta dada pelo Divino Espírito Santo à prece que lhe foi feita.

Com a promessa paga, o compromisso do encarregado estava concluído. A certeza de obrigação cumprida não era suficiente para Seu Benedito deixar de executar o papel de festeiro, encargo que desempenhava há muitas décadas. A responsabilidade seria transferida à filha, que tivera um problema, levando-o a pedir uma graça ao Divino, que receberia o agradecimento em forma de festa. O prestígio adquirido por Seu Benedito ao longo das décadas em que atuou como encarregado da festa da Barreira Funda e o papel por ele desempenhado como líder sindical e do movimento quilombola se somavam a isso. A organização da festividade conferia esse prestígio, o que se atualizava anualmente como momento de projeção para ele, para a família e para a comunidade.

\section{A prece, a dádiva e o Divino entre os humanos}

Festas que se referem à religiosidade popular têm sido objeto de pesquisas etnográficas com enfoques distintos, articulando relações entre religião, cultura e sociedade. Neste artigo pretendo recuperar alguns dados levantados a partir da participação em duas Festas do Divino no território quilombola de Santa Rosa dos Pretos e analisá-los com base em dois conceitos antropológicos, a saber: a "dádiva" e a "prece”. A reflexão empreendida por Marcel Mauss (2009) sobre esses dois fenômenos é que "são por si mesmos muito complexos", são relações, e "tudo neles se mistura". São tratados como "fatos sociais totais", pois

exprimem, ao mesmo tempo e de uma só vez, toda espécie de instituições: religiosas, jurídicas, morais (políticas e familiais ao mesmo tempo), econômicas (produção e consumo, prestação e distribuição), sem falar das dimensões estéticas e morfológicas das próprias instituições. (MAUSS, 2003, p. I87).

Gonçalves e Contins (2008), assim como Ferreti (2005), consideram a Festa do Divino um ritual que faz parte do catolicismo popular, destacando as especificidades das celebrações de acordo com as regiões onde acontecem. No que se referem ao Maranhão, essas diferenças podem ser notadas em aspectos como a definição do calendário de celebrações. Essa festividade faz parte do calendário religioso de terreiros de Tambor de Mina, seja na zona central de São Luís, em bairros do entorno, como Liberdade, Camboa, Fé em Deus etc., seja no interior. Em Alcântara, a comemoração se aproxima mais do catolicismo. 
Ao comentarem acerca da noção de fato social total, Gonçalves e Contins (2008) assinalam que essa noção diz respeito a possíveis dificuldades que podemos encontrar, como observadores e analistas, na identificação de "fronteiras muito bem delimitadas entre aquilo que é por nós classificado como uma atividade propriamente 'técnica' ou 'estética' e atividades que classificaríamos como mágico-religiosas" (p. 67).

Tal como ocorre em outras festividades populares, as etapas da Festa do Divino demandam uma série de elementos simbólicos e rituais cuja aquisição ou confecção dependa de referência recorrente ao termo promessa. Os estudos sobre a Festa do Divino permitem uma especulação a respeito do modo como essa promessa é feita. Ao considerarmos que a abertura da tribuna é o momento em que, para os devotos, é aberto o canal de comunicação com o Espírito Santo podese compreender que esse é um momento propício para se fazer súplicas, pedidos e rogos ao "Divino". Nessa relação entre humanos e seus "deuses", a prece é uma forma privilegiada de comunicação, daí a eficácia da palavra e a possibilidade de estabelecimento de vínculos entre as duas categorias.

Esse compromisso com o pagamento de promessa ajuda a perceber a prece como ato de linguagem por excelência, que não escapa ao pressuposto geral da ajuda mútua (PINA-CABRAL, 2009). A retribuição se inscreve nesse mesmo horizonte de sentido, pois "a mesma troca que me faz anfitrião, faz-me também um hóspede potencial. Isto ocorre porque 'dar e receber' implica não só uma troca material, mas também uma troca espiritual, uma comunicação entre almas" (LANA, 2000, p. I79).

A certeza da resposta a uma prece vem da devoção, da experiência comunitária, dos relatos partilhados e da participação na (e da) Festa como devoto(a), desempenhando o papel ou o cargo que for: mordomo, imperador, imperatriz, cozinheiro, folião, salveiro, remeiro ou cavaleiro. Essa relação converge em uma troca simbólica entre o Divino Espírito Santo e seus devotos. Fé e adoração ao Divino estão intrinsecamente relacionadas e explicam a existência da festa, que é também um forte componente identitário na região.

De acordo com Mauss (2009), de todos os fenômenos religiosos, "é a prece que apresenta imediatamente a impressão de vida, riqueza e complexidade" (p. 774). A Festa do Divino tem na prece um dos seus elementos fundadores, posto estar relacionada ao pagamento de promessa. Outra característica da prece destacada por Mauss (2009) é a flexibilidade, e aqui mais uma vez é possível considerar as variadas formas de se pedir favor ou graça ao Divino Espírito Santo. A prece teria, na opinião de Mauss (2003), papéis diversos, e a promessa representa "um contrato, um 
ato de fé, uma confissão, uma súplica, um elogio". ${ }^{8}$ Já a concepção de dádiva está intrinsecamente relacionada, na abordagem de Mauss (2003), com a ideia de que as trocas e os contratos se fazem sob a forma de presentes, obrigatoriamente dados e retribuídos. ${ }^{9}$ No conjunto complexo de temas de “coisas sociais em movimento", Mauss destaca a importância do "caráter voluntário, aparentemente livre e gratuito, e, no entanto, obrigatório e interessado dessas prestações" (p. 187-200).

A comensalidade está diretamente relacionada a outro momento fundamental que é o sacrifício. Tal como no potlatch, a forma de agradecimento e dispensação material é sinal de prestígio; assim analisada com base no livro Ensaio sobre a dádiva (MAUSS, 2003) e na teoria da prece, a comensalidade é a expressão da eficácia da palavra na relação com o Divino Espírito Santo. A abordagem de Mauss nos leva a considerar que a eficácia da palavra, que se expressa na resposta a uma súplica ou a um pedido, é o que motiva a comemoração. $O$ ato de dar não é um ato desinteressado, podendo se associar em maior ou menor grau a uma ideologia da generosidade, mas de qualquer modo não existe dádiva sem expectativa de retribuição (LANA, 2000).

É possível estabelecer um paralelo entre o sentido do pagamento da promessa, da esmola e da joia do Divino e o circuito da troca de um objeto, conforme assinalado por Mauss (2003). A promessa representa o compromisso assumido por uma das partes da relação, que no caso é o recebedor(a) da graça concedida pelo Divino. Assim como o objeto trocado, o pagamento da promessa é o reconhecimento da manifestação da graça recebida e a manutenção da dádiva. $\mathrm{O}$ objeto trocado não permanece com a pessoa que é sua depositária, mas termina de algum modo retornando com mais valor do que foi oferecido, assim como a festa.

O pagamento de promessa é uma retribuição a um pedido respondido. A obrigatoriedade da retribuição é instaurada como agradecimento ao Divino e demonstra a disposição em se fazer o melhor, independentemente das possibilidades e dos recursos financeiros. $\mathrm{O}(\mathrm{A})$ encarregado(a) não paga promessa sozinho(a), pois recebe ajuda e doações de outros devotos que desejam agradar ao Divino Espírito Santo. A responsabilidade da organização é de quem paga a promessa, mas a relação com o Divino não é exclusiva e tampouco circunscrita ao encarregado.

Tudo o que existe pode se transformar em "coisa a ser dada e retribuída" - palavras, bens, pessoas. As coisas que podem ser dadas e retribuídas tratam-se, antes de tudo, de "gentilezas,

\footnotetext{
${ }^{8}$ Pina-Cabral (2009, p. 18), revisitando este texto de Mauss, afirma que a palavra portuguesa "prece” é essencialmente latina e que, no plural, "preces", significa "súplicas, pedidos, rogos, instâncias".

${ }^{9}$ A análise de Mauss (2003) está baseada no potlatch, termo que, segundo o autor, quer dizer “'nutrir, 'consumir”” (p. 191). A complexidade da ideia de dádiva, referida a esse ritual, permite um paralelo com a Festa do Divino.
} 
banquetes, ritos, serviços militares, mulheres, crianças, danças, festas, feiras em que o mercado é apenas um dos momentos onde a circulação de riqueza constitui apenas um termo de um contrato muito mais geral e permanente" (LANA, 2000, p. 19I) $\cdot{ }^{10}$ De acordo com Lana (2000), a dádiva foi definida por Mauss de modo amplo, abarcando, além de presentes, "visitas, festas, comunhões, esmolas, heranças, um sem número de 'prestações' enfim — prestações que podem ser 'totais' ou 'agonísticas', e é neste rol que está incluído o potlatch dos índios do noroeste americano" (p. I75).

$\mathrm{Na}$ Festa do Divino, tal como em outras festividades populares, "as atividades técnicas, estéticas, econômicas, fisiológicas e psicológicas que desencadeiam a comemoração são realizadas como uma contradádiva oferecida ao Divino Espírito Santo, em agradecimento pelas graças concedidas". A festa é o tempo em que se vive, se vê e se lê na paisagem local, de modo ritualizado, algumas referências cotidianas de sociabilidade. O costume da "promessa", no sentido antropológico conferido por Mauss (2009), assim como o compromisso de realizar o "pagamento" da promessa, se inscreve na lógica de uma contradádiva oferecida ao Divino Espírito Santo, em agradecimento pelas graças concedidas (GONÇALVES; CONTINS, 2008).

\section{Considerações finais}

O universo das comunidades quilombolas maranhenses é composto de um rico repertório de bens e práticas culturais, de atividades que permitem perceber, dentre outros aspectos, que o cotidiano é atravessado por diversos momentos em que são fomentados solidariedade e apoio mútuo. No que se refere às festividades, é possível observar que são espaços importantes de diálogo e intercâmbio, reforçam a sociabilidade por meio de encontros entre aqueles que permanecem na comunidade e os que vivem fora dela. As relações e os vínculos mantidos com comunidades quilombolas de Itapecuru Mirim e também de cidades próximas, com instituições sociais e entre líderes de outras comunidades são partes do processo de formação política e social permanentes.

A Festa do Divino expressa uma forma de viver e pensar trazida de Portugal que ao aportar no Brasil sofreu adaptações. Tem sido mantida em muitas comunidades quilombolas graças às adaptações que fazem parte de um processo de reposição cultural que representa continuidades com a cultura de expressão portuguesa, mas com rupturas que permitiram a introdução de elementos

\footnotetext{
10 Lana (2000) sustenta, referindo-se ao Ensaio sobre a dádiva (1978), que Mauss generaliza a noção de contrato ao mesmo tempo que a reformula e lembra que "é exatamente esse contrato maussiano que Lévi-Strauss substituirá pelo princípio de reciprocidade” (p. 179).
} 
culturais do repertório de matriz africana, a exemplo da participação de entidades não católicas, como os encantados. Não obstante, não se pode afirmar que se trata de uma manifestação que possa ser inscrita em um quadro cultural de tradição "sincrética", mas que pode ser compreendida no horizonte dos contatos entre a religião católica e as tradições religiosas de matriz africana, no qual contam separação e composição. A partir dos paralelos estabelecidos entre a interpretação feita por Marcel Mauss da dádiva e da prece, procurei assinalar que a Festa do Divino é significativa na constituição da vida social da comunidade quilombola Santa Rosa dos Pretos.

Se os mares permitiram a travessia das grandes devoções e do cosmos, os rios funcionaram como canais ajudando a fixar devoções e a cosmovisão dos escravizados depois da travessia do Atlântico. Ao enfrentar a viagem rio abaixo ou rio acima, dependendo da região para onde era levado, o barco poderia tombar, adernar ou ser tomado de assalto. Os fluxos e as forças presentes naquelas terras atravessavam os caminhos percorridos pelos forasteiros que ali se estabeleceram. Se os riscos estavam sempre presentes, as formas de enfrentá-los também estavam.

Nesses fluxos que ajudaram na desterritorialização do sagrado, representando perigos cósmicos, certamente havia a participação dos invisíveis que acompanharam os traslados de uma parte a outra, até mesmo nos barcos que atravessavam os rios das cidades onde a "encantaria maranhense", não por acaso, é tão presente, como Itapecuru Mirim e outras cidades cortadas pelo Itapecuru e tantos outros rios maranhenses. O culto ao Divino se interiorizou nesse mesmo fluxo com participação de encantados na vida dos quilombolas, uma vez que humanos e aqueles entes habitam os mesmos territórios.

As partilhas e a abundância são importantes para a compreensão de toda a produção e organização de uma festividade. Assim como a esmola e a joia doada ao Divino Espírito Santo, chama atenção a fartura de alimentos e bebidas. Essa abundância pode ser observada à mesa do Império, na quantidade e na qualidade da comida e dos doces, especialmente dos bolos. Estes são delicada e criativamente decorados com elementos simbólicos que remetem ao Divino, como a pomba e a recorrência de enfeites e adereços nas cores vermelha e branca. $\mathrm{O}$ abate solene do boi e do porco, em uma cena em que a música das caixeiras serve como trilha, remete ao sacrifício. É o momento da sacralização de parte do alimento a ser consumido no banquete partilhado com convidados. A fartura é uma demonstração de generosidade e de abundância, e principalmente expressa a intenção de partilhar a satisfação com o Divino Espírito Santo. Pelo ato da fala, um favor é pedido, por isso parece-me que a força da retribuição tem tanto potencial explicativo quanto a ideia de ostentação que está mais próxima de algumas interpretações sobre o potlatch. Assim, a grande distribuição de alimentos na Festa do Divino pode ser pensada como uma 
maneira de oferecer potlatch, porém não como mera preocupação de superarem-se uns aos outros em generosidade em cada festa.

Ser encarregado(a) de um festejo demanda recursos e a poios e disposição para consegui-los. Para Seu Benedito, o importante é a celebração como atividade que integra a identidade da comunidade onde ele mora. Se a vaidade faz parte da percepção sobre o prestígio, ela estaria mais relacionada com o fato de se ter logrado organizar um evento importante na (e para a) comunidade do que com a ideia de ostentação. Apesar dos custos e das despesas que acarreta, a demonstração de poder econômico ou vontade de ofuscar o outro não parece ser o que mobiliza esse encarregado.

\section{Referências}

ALMEIDA, A. W. B. de. Autonomia e mobilização política no Maranhão. Rio de Janeiro: Casa 8, 2015.

ANJOS, J. C. dos; ORO, A. P. Festa de Nossa Senhora dos Navegantes em Porto Alegre: sincretismo entre Maria e Iemanjá. Porto Alegre: Editora da Cidade, 2009.

CARVALHO, C. de M. B. de; SÁ, L. A dádiva e o divino: a importância do ritual para a manutenção da vida social. Revista Interdisciplinar em Cultura e Sociedade, São Luís, v. 3, número especial, jul./dez. 20I7. Disponível em: <http://www.periodicoseletronicos.ufma.br/>. Acesso em: 23 abr. 2018.

FERRETI, M. Encantados e encantarias no folclore brasileiro. 2008. Trabalho apresentado ao VI Seminário de Ações Integradas em Folclore, São Paulo, 2008. p. I-6. Disponível em: <http://gurupi.ufma.br/>. Acesso em: 20 abr. 2018.

FERRETI, M. Pureza nagô e nações africanas no tambor de mina do Maranhão. Ciências Sociaise Religião, Porto Alegre, ano 3, n. 3, p. 75-94, 2001.

FERRETI, S. F. Catálogo da exposição Divino Toque do Maranhão. Rio de Janeiro: Centro Nacional de Folclore e Cultura Popular/IPHAN/MEC, 2005.

FERRETI, S. F. Repensando o sincretismo. A Casa das Minas de São Luís do Maranhão. São Paulo: EDUSP; Fapema, 1995.

GONÇALVES, J. R. Santos; CONTINS, M. Entre o divino e os homens: a arte nas festas do Divino Espírito Santo. Horizontes Antropológicos, Porto Alegre, v. I4, n. 29, p. 67-94, jun. 2008. Disponível em: $<$ http://www.scielo.br/scielo $>$. Acesso em: 2 mai. 2018. 
LANA, M. Nota sobre Marcel Mauss e o ensaio sobre a dádiva. Revista de Sociologia e Política, Curitiba, ano I4, p. I73-194, jun. 2000.

LUCINDA, M. da C. Práticas culturais, relações políticas e estratégias de luta por direito à territorialidade. Revista da Associação Brasileira de Pesquisadores Negros, edição especial, caderno temático Saberes Tradicionais, v. 9, p. 224-249, 2017. Disponível em: <http://abpnrevista.org.br/revista/>. Acesso em: 23 abr. 2018.

MAUSS, M. A oração. Introdução geral. Tradução Mauro Guilherme Pinheiro Koury. Revista Brasileira de Sociologia da Emoção, João Pessoa, v. 8, n. 24, p. 774-788, 2009. Disponível em: $<$ https://tendimag.files.wordpress.com>. Acesso em: 23 abr. 2018.

MAUSS, M. A prece. In: OLIVEIRA, R. C. Mauss. São Paulo: Ática, I979. (Coleção Grandes Cientistas).

MAUSS, M. Ensaio sobre a dádiva. Forma e razão da troca nas sociedades arcaicas. São Paulo: Cosac Naif, 2003. (Coleção Sociologia e Antropologia).

MBEMBE, A. Crítica da razão negra. São Paulo: N-I Edições, 2018.

NUNES, P. P. Canelatiua, terra dos pobres, terra da pobreza: uma territorialidade ameaçada, entre a recusa de virar terra da base e a titulação como terra de quilombo. 20II. Tese (Doutorado) Programa de Pós-Graduação em Antropologia, Universidade Federal Fluminense, Niterói, 2OII.

OPIPARI, C. O candomblé - imagens em movimento. São Paulo: Edusp, 2009.

PACHECO, G.; GOUVEIA, C.; ABREU, M. C. Caixeiras do Divino Espirito Santo de São Luís do Maranhão. Rio de Janeiro: Associação Cultural Caburé. Disponível em: $<$ http://www.museuafro.ufma.br/>. Acesso em: 22 jul. 2020.

PINA-CABRAL, J. de. A prece revisitada: comemorando a obra inacabada de Marcel Mauss. Religião e Sociedade, Rio de Janeiro, v. 29, n. 2, p. 13-28, 2009.

PRANDI, R.; SOUZA, P. R. de. Encantaria de Mina em São Paulo. In: Encantaria brasileira: o livro dos mestres, caboclos e encantados. Rio de Janeiro: Pallas, $200 I$.

SERRA, O. Águas do rei. Petrópolis: Vozes; Koinonia, I995. 